\title{
NOTA
}

\section{DEFICIÊNCIA DE BORO EM SOJA (1)}

\author{
HIPÓLITO ASSUNÇĀO ANTONIO MASCARENHAS $(2,5)$, \\ MANOEL ALBINO COELHO DE MIRANDA $(2,5)$, ONDINO CLEANTE BATAGLIA $\left({ }^{3,5}\right)$, \\ JOSÉ CARLOS VILA NOVA ALVES PEREIRA $\left({ }^{4}\right)$ e ROBERTO TETSUO TANAKA $\left({ }^{2,5}\right)$
}

\begin{abstract}
RESUMO
A deficiência de boro é rara na cultura da soja no Brasil. A deficiência aqui descrita ocorreu em Guaíra, SP, numa várzea onde houve excessiva aplicação de calcário, elevando a saturação por bases a valores próximos de $90 \%$. Nas áreas deficientes, o teor de boro no solo foi de $0,06 \mathrm{ppm}$ e nas áreas aparentemente sem sintomas, $0,11 \mathrm{ppm}$. Nas folhas das plantas com sintomas, a concentração era de 10 ppm de boro e nas sem sintomas, de $19 \mathrm{ppm}$. Nas plantas deficientes, as folhas primárias eram cariáceas e espessas, e houve morte da gema apical, com brotamento de gemas laterais, nanismo, poucas flores e pequeno pegamento de vagens, com sensivel redução na produtividade.
\end{abstract}

Termos de indexação: soja, boro, calagem. nas (SP).

(1) Recebido para publicação em 24 de junho e aceito em 5 de outubro de 1988.

(2) Seção de Leguminosas, Instituto Agrơnómico de Campinas (IAC), Caixa Postal 28, 13001 Campi-

(3) Seçāo de Fertilidade do Solo e Nưtiçăo de Plantas, IAC.

(4) Estação Experimental de Ribeirâo Preto, IAC.

(5) Com bolsa de pesquisa do CNPq. 
A deficiência de boro geralmente ocorre em solos alcalinos ou com elevado teor de matéria orgânica (PERVIS \& HANNA, 1939). Deve-se considerar ainda que a quantidade de boro necessária ao desenvolvimento de sementes e produção de grãos é superior àquela exigida somente para o desenvolvimento vegetativo da planta (MARSCHNER, 1986).

O objetivo deste trabalho foi verificar se os sintomas nas folhas de soja observados em solo drenado de várzea em Guaira eram de deficiência de boro.

\section{Material e Métodos}

Na Fazenda Rodeio, em Guaíra, SP, fez-se a sistematização e drenagem de uma várzea para plantio de arroz. Entretanto, como a vazão de água era limitante para 0 arroz, cultivou-se soja. Pela amostra de solo A observa-se que o solo era ácido, com pH 4,7 e indice de saturação por bases (V\%) de $37 \%$ (Quadro 1). Aplicaram-se 12t/ha de calcário dolomítico em junho de 1987 e plantou-se soja, cultivar IAC-8, em agosto, utilizando-se na adubaçāo $400 \mathrm{~kg} / \mathrm{ha}$ da fórmula 0-20-10. Constatou-se deficiência de boro em cinco dos 120 ha cultivados com soja. Foi feita amostragem a $0-20 \mathrm{~cm}$ de profundidade e análise do solo segundo método de RAIJ \& QUAGGIO (1983), onde as plantas mostravam ou não sintomas de deficiência de boro. Efetuou-se a determinação de boro através da extração com solução de $\mathrm{CaCl}_{2} 0,0 \mathrm{I} \mathrm{M}$, na proporção de $20 \mathrm{~cm}^{3}$ de solo para $40 \mathrm{~cm}^{3}$ de extrator, e fervura por cinco minutos de carvão ativado. Depois de filtrado, determinou-se 0 boro usando o reagente azometino- $\mathrm{H}$, em procedimento semelhante ao descrito por PARKER \& GARDNER (1981). Aos 55 dias após a germinação, pouco antes do início do florescimento, foi feita amostragem das folhas: estas foram lavadas com água destilada, secas a $60^{\circ} \mathrm{C}$ e moídas em moinho tipo Wiley, efetuando-se as análises de macro e micronutrientes, conforme métodos de BATAGLIA et al. (1983).

\section{Resultados e Discussão}

As amostras dos solos AC e AS - Quadro 1 - apresentam altos teores de cálcio e magnésio e, conseqüentemente, valores elevados de $\mathrm{V} \%$, devido ao excesso de calcário aplicado. Apresentam ainda um desbalanço entre os teores de $\mathrm{Ca}, \mathrm{Mg}$ e $\mathrm{K}$, enquanto os teores de boro e de manganês são baixos (SIQUEIRA, 1987).

No quadro 2, nota-se que os valores de potássio e manganês no tecido das duas amostras estão igualmente baixos, confirmando os dados da análise de solo. O mesmo ocorreu em relação ao boro, para as folhas de primeira amostra, cujo teor é considerado deficiente, enquanto na outra é considerado apenas baixo, conforme a tabela de Jones, citado por OHLROGGE \& KAMPRATH (1968). 
QUADRO 1. Análise química do solo em amostras colhidas antes da aplicação (A), após a aplicação em áreas com sintomas agudos de deficiência (AC) e após a aplicação em áreas aparentemente sem sintamas nas plantas (AS)

\begin{tabular}{|c|c|c|c|c|c|c|c|c|c|}
\hline Amostra & $\mathrm{pH}$ & MO & $P$ & $K$ & $\mathrm{Ca}$ & $\mathrm{Mg}$ & V & $\mathrm{B}$ & $\mathrm{Mn}$ \\
\hline & & $\%$ & $\mu \mathrm{g} / \mathrm{cm}^{3}$ & \multicolumn{3}{|c|}{$-\mathrm{meq} / \mathrm{cm}^{3}$} & $\%$ & $\longrightarrow p$ & - \\
\hline A & 4,7 & 4,4 & 8,0 & 0,12 & 1,8 & 0,5 & 37,0 & $\cdots$ & $\ldots$ \\
\hline$A C$ & 6,3 & 4,5 & 18,0 & 0,11 & 8,4 & 4,8 & 89,0 & 0,06 & 2,8 \\
\hline AS & 6,0 & 4,8 & 78,0 & 0,21 & 9,4 & 4,0 & 87,0 & 0,11 & 3,2 \\
\hline
\end{tabular}

... dado năo determinado.

QUADRO 2. Análise de folhas de soja cultivar IAC-8 colhidas de plantas com sintomas de deficiência aguda de boro $(A C)$ ou de plantas aparentemente sem sintomas de deficiência (AS)

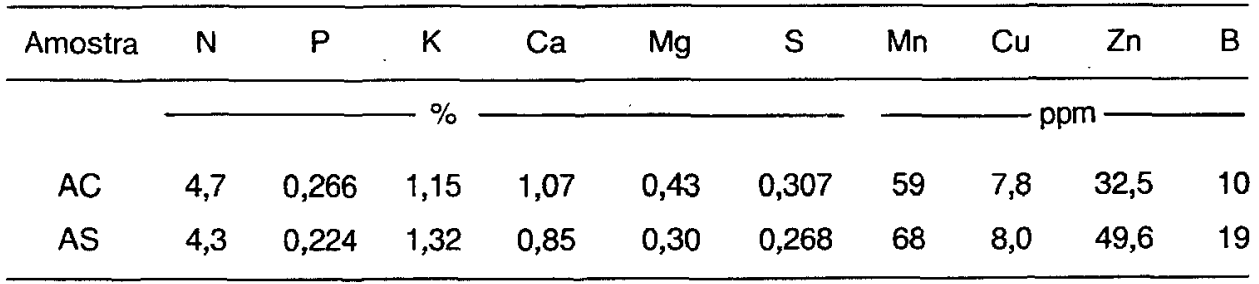

Em condições de várzea, os sintomas de deficiência de boro em soja são observados em reboleiras, em plantas com vários graus de deficiência, desde agudo até plantas praticamente sadias. Para melhor caracterização da síndrome, semeou-se, em condiçōes de estufa, o cultivar IAC-9 em vasos preenchidos com solo coletado nessas reboleiras, à profundidade de $0-20 \mathrm{~cm}$. Após o desbaste, deixaram-se quatro plantas por vaso. Na deficiência aguda de boro, não houve formaçāo de folhas primárias e a plântula apresentou apenas as folhas cotiledonárias (Figura 1). Em condiçōes menos severas, observou-se a presença de folhas primárias, porém com morte da gema apical (Figura 2). Na deficiência menos intensa de boro, mesmo com morte da gema apical, a plântula formou novas gemas laterais. Entretanto, por diminuição da multiplicação celular, tais gemas se desenvolveram até a formação de pequenas folhas, e o seu desenvolvimento posterior foi paralisado, caracterizando uma situação de superbrotamento. Em decorrência do pequeno desenvolvimento das plantas, as folhas primárias tornaram-se coriáceas e espessas (Figura 3). Na figura 4, observam-se diferentes niveis de deficiência de boro em plântulas de soja com a mesma idade. 


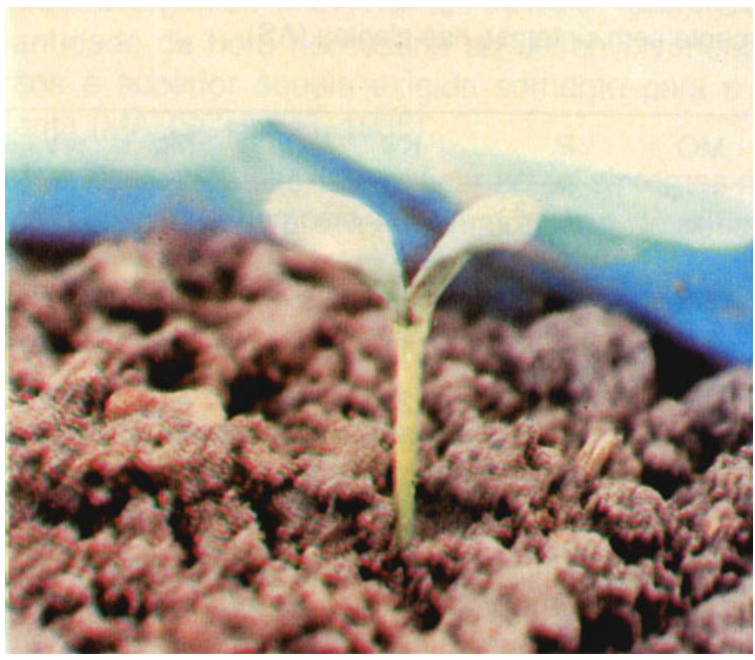

FIGURA 1. Plântula apresentando apenas folhas cotiledonárias com morte da gema apical

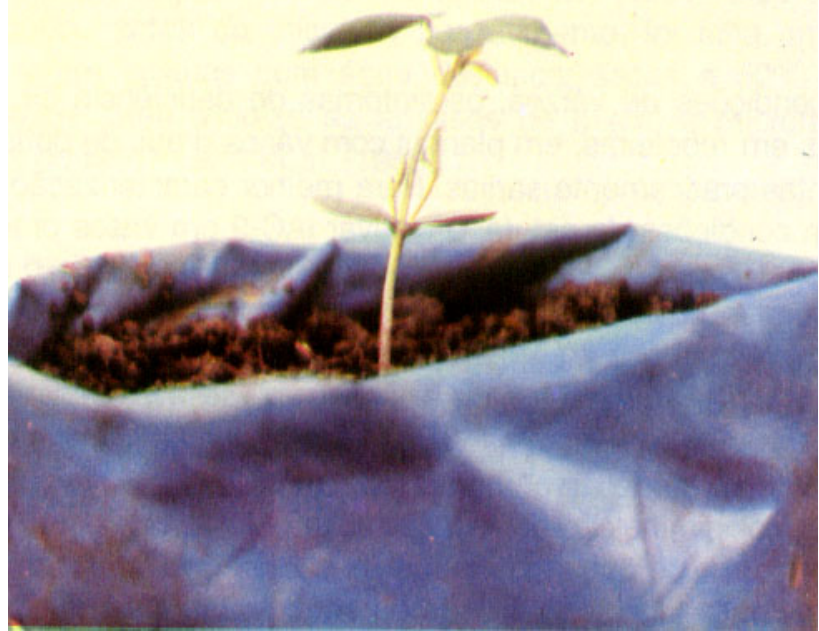

FIGURA 2. Plântula com folhas primárias e morte da gema apical e brotamento de gemas axilares das folhas cotiledonárias. 


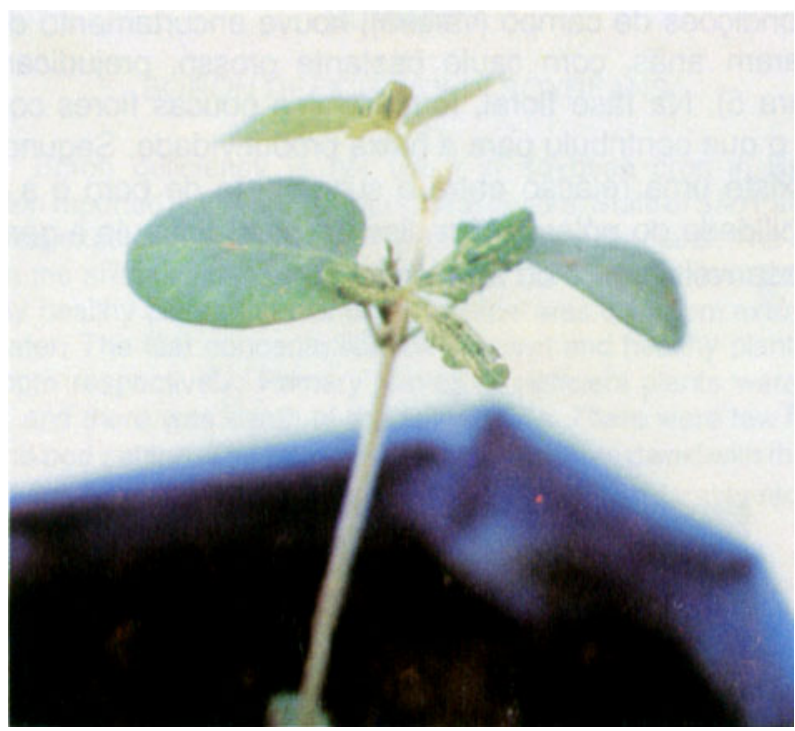

FIGURA 3. Má formação de folíolos dos brotos e, conseqüentemente, paralisação do crescimento, propiciando o desenvolvimento de novas gemas laterais, caracterizando superbrotamento.

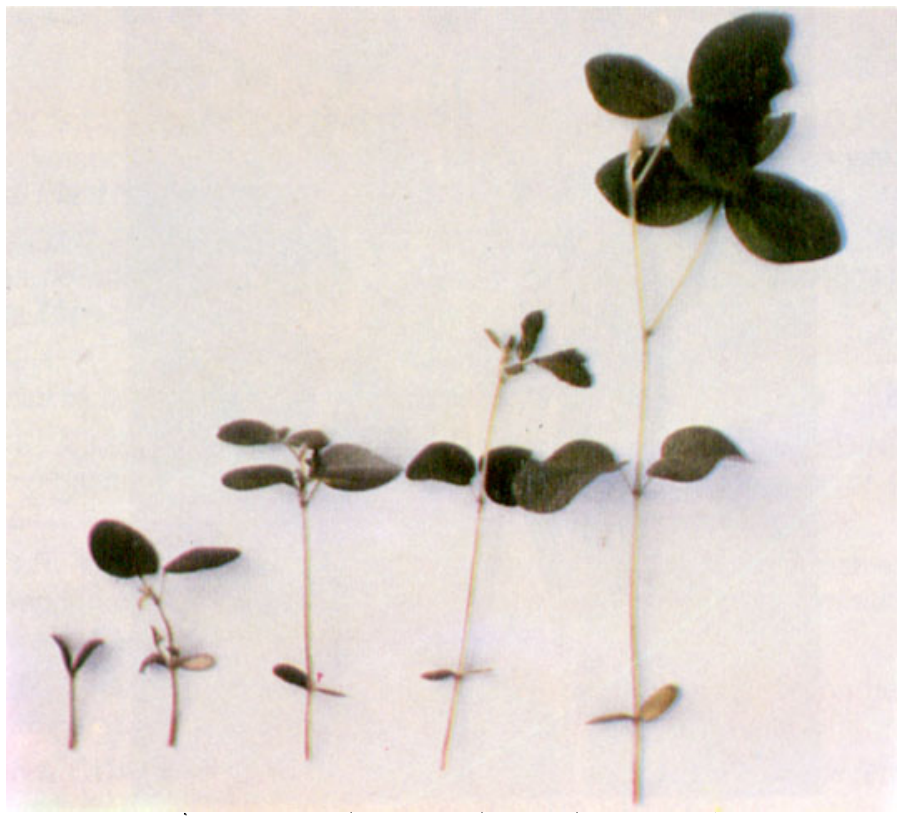

FIGURA 4. Diferentes intensidades de deficiência de boro em plântulas da mesma idade, sendo a da direita considerada normal. 
Em condições de campo (várzea), houve encurtamento de internódios e as plantas ficaram anãs, com caule bastante grosso, prejudicando a colheita mecânica (Figura 5). Na fase floral, formaram-se poucas flores com baixo índice de pegamento, o que contribuiu para a baixa produtividade. Segundo AGARWALA et al. (1981), existe uma relação entre o suprimento de boro e a capacidade de produçāo e viabilidade do pólen. Além disso, o boro estimula a germinação, particularmente o desenvolvimento do tubo polínico.

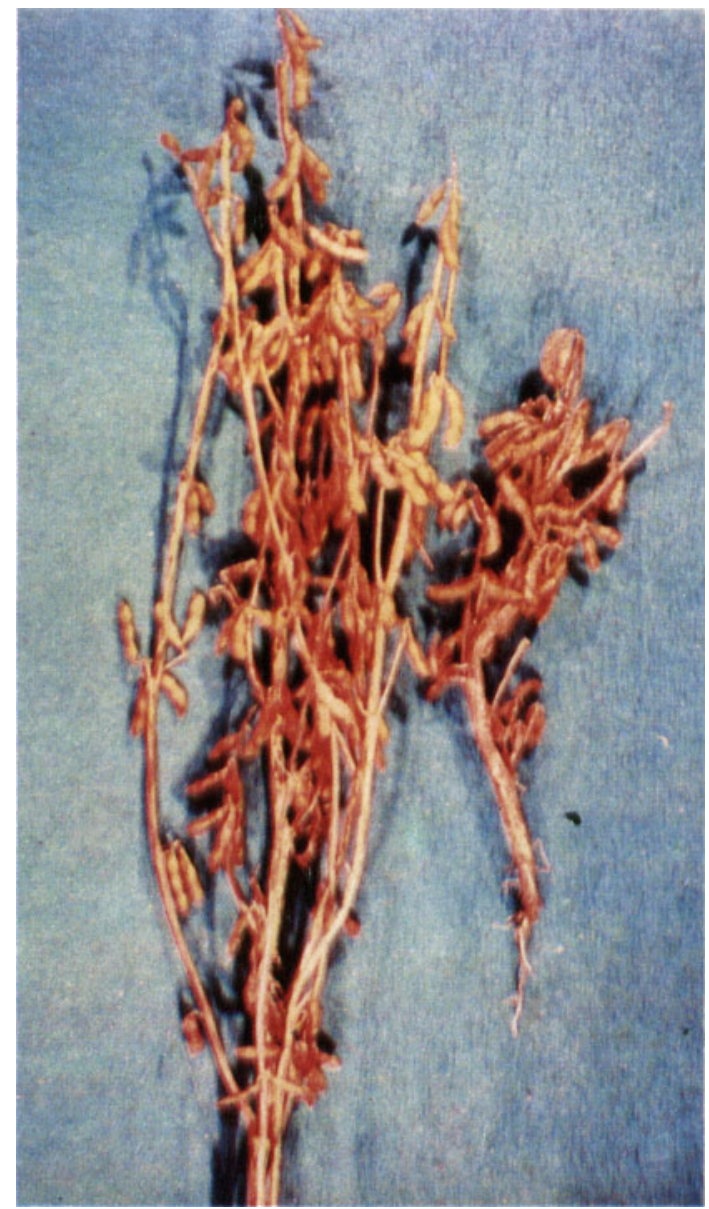

FIGURA 5. À esquerda, planta normal, e, à direita, com nanismo, caracterizado por internódios curtos. 


\section{SUMMARY \\ BORON DEFICIENCY IN SOYBEANS}

Boron deficiency is not usual in soybean crop in Brazil. The observation reported in this article occurred at Guaira, State of São Paulo, Brazil on a low flat excessively limed and high in organic matter land. The soil boron content in the areas with plant deficiency was $0.06 \mathrm{ppm}$ while in the areas of apparently healthy plants the soil boron content was $0.11 \mathrm{ppm}$ extracted with boiling water. The leaf concentration for deficient and healthy plants was 10 and $19 \mathrm{ppm}$ respectively. Primary leaves of deficient plants were leathery and thick and there was death of the apical buds. There were few flower formation and pod setting. The boron deficient plants were dwarf with thick stems creating difficulty at harvest and soybean yield was considerably reduced.

Index terms: soybeans, boron, liming.

\section{AGRADECIMENTO}

Os autores agradecem a colaboração da Técnica de Laboratório Sonia Maria Pierro Falivene e da Auxiliar de Laboratório Angela Maria Caldeira da Silva, e aos Auxiliares Agropecuários III Aparecido da Silva e Valdeir Biudes Hermoso, a dedicação na execução deste trabalho.

\section{REFERÊNCIAS BIBLIOGRÁFICAS}

AGARWALA, S.C.; SHARMA, P.N.; CHATTERJEE, C. \& SHARMA, C.P. Development and enzymatic changes during pollen development in boron deficient maize plants. Journal Plant Nutrition, 3:329-336, 1981.

BATAGLIA, O.C.; FURLANI, A.M.C.; TEIXEIRA, J.P.F.; FURLANI, P.R. \& GALLO, J.R. Métodos de análise química de plantas. Campinas, Instituto Agronômico, 1983. 48p. (Boletim Técnico, 78)

MARSCHNER, $H$. Functions of mineral nutrients: micronutrients. In: - Mineral nutrition of higher plants. London, Academic Press, 1986. Chap. 9, p.321-334.

OHLROGGE, A.J. \& KAMPRATH, E.J. Fertilizer use in soybeans. In: DINAUR, R.C., ed. Changing patterns in fertilizer use. Madison, Soil Science Society of America, 1968. p.275-295.

PARKER, D.R. \& GARDNER, E.H. The determination of hot-water soluable boron in some acid Oregon soils using a modified azomethine-H procedure. Communications in Soil Science and Plant Analysis, 12(12):1311-1322, 1981.

PERVIS, E.R. \& HANNA, W.J. The influence of overliming upon boron deficiency. The American Fertilizer, 91:5-8, 1939.

RAIJ, B. van \& QUAGGIO, J.A. Métodos de análise de solo para fins de fertilidade. Campinas, Instituto Agronômico, 1983. 31p. (Boletim Técnico, 81)

SIQUEIRA, O.J.F. de. Recomendação de adubação e calagem para os Estados do Rio Grande do Sul e Santa Catarina. Passo Fundo, EMBRAPA-CNPT, 1987. 100p. 